\title{
Artikel
}

\section{De stand van de stelselherziening: het primaat bij de senaat}

\author{
Mr. H.W. (Wilco) de Vos*
}

\section{Inleiding}

Aan het slot van het afgelopen parlementaire jaar zijn er bij de totstandkoming van het nieuwe stelsel van omgevingsrecht de nodige resultaten geboekt. Zo is het voorstel tot wijziging van de Crisis- en herstelwet (Chw), ook wel 'de Transitiewet' genoemd, aangenomen door de Eerste Kamer. De wet ${ }^{1}$ is op 19 juni 2019 in werking getreden. Verder zijn de voorstellen voor de Aanvullingswetten natuur en geluid ${ }^{2}$ door de Tweede Kamer aangenomen en zijn de ontwerpen van het Invoeringsbesluit en de Aanvullingsbesluiten bodem en natuur bij het parlement voorgehangen.

Dit betekent dat er momenteel vier wetsvoorstellen ${ }^{3}$ en drie ontwerpbesluiten in behandeling zijn bij de Eerste Kamer. Dat geldt ook voor het voorstel voor de Aanvullingswet grondeigendom, ${ }^{4}$ zodra dat door de Tweede Kamer wordt aangenomen. Verder volgt de komende

* Mr. H.W. de Vos is werkzaam bij de directie Constitutionele Zaken en Wetgeving van het Ministerie van Binnenlandse Zaken en Koninkrijksrelaties en is als juridisch projectleider betrokken bij de totstandkoming van de nieuwe omgevingswetgeving. Het artikel is op persoonlijke titel geschreven. De tekst van dit artikel is afgesloten op 15 september 2019.

1. Wet van 29 mei 2019 tot wijziging van de Crisis- en herstelwet in verband met het versnellen van woningbouw en het faciliteren van duurzame ontwikkeling, zoals het verduurzamen van het energiegebruik (Stb. 2019, 216)

2. De volledige citeertitel van de Invoeringswet, het Invoeringsbesluit en de Invoeringsregeling en de aanvullingswetten, -besluiten en -regelingen is met de toevoeging 'Omgevingswet'. Die toevoeging blijft in dit artikel achterwege.

3. De voorstellen voor de Invoeringswet en de Aanvullingswet bodem waren al bij de Eerste Kamer aanhangig.

4. Kamerstukken II 2018/19, 35 133, nrs. 1-2. maanden de voorhang van de ontwerpen van de Aanvullingsbesluiten geluid en grondeigendom. Het zwaartepunt van de parlementaire behandeling ligt dit najaar dan ook bij de Eerste Kamer. De senaat heeft op 10 september 2019 enkele keuzes gemaakt over de wijze en planning van de behandeling. ${ }^{5}$ Daarbij zullen wetsvoorstellen en de bijbehorende ontwerp-AMvB's gecombineerd worden behandeld. Met de door de Eerste Kamer voorziene planning blijft de beoogde inwerkingtreding van het stelsel per 1 januari 2021 in het vizier.

Het proces op weg naar de inwerkingtreding van het nieuwe stelsel verloopt stapsgewijs. In de voortgangsbrief van eind van dit jaar zal de Minister van Binnenlandse Zaken en Koninkrijksrelaties (BZK), een jaar voor de beoogde datum, de voortgang schetsen. Belangrijke onderdelen naast de wetgeving zijn: de stand van zaken van de implementatie en de oplevering van de landelijke voorziening van het Digitaal Stelsel Omgevingswet (DSO). Medio 2020, een halfjaar voor de beoogde datum van inwerkingtreding, volgt de voorhang bij het parlement van het ontwerp van het inwerkingtredings-KB voor de Omgevingswet. Dat zal opnieuw vergezeld gaan van een rapportage aan beide Kamers van de stand van zaken. Vervolgens kan daarover in het parlement het debat worden gevoerd.

Ter voorbereiding op de transitie naar het nieuwe stelsel wordt in interbestuurlijk verband hard gewerkt aan de implementatie bij gemeenten, waterschappen, provincies en het Rijk en aan de ontwikkeling van het DSO. Onderdeel van de transitie is ook het overgangsrecht dat in het invoeringsspoor is opgenomen. Daarin wordt bijvoorbeeld bepaald dat gemeenten tot 2029 de tijd

5. Brief van 13 september 2019, kenmerk 164662.11u, www.eerstekamer.nl/kamerstukdossier/omgevingsrecht. 
hebben om hun omgevingsplannen aan te passen. Dit draagt bij aan een zorgvuldig proces van invoering. Niettemin moeten partijen in de uitvoeringspraktijk voldoende voorbereid zijn om op het moment van inwerkingtreding aan de slag te kunnen gaan. In de voortgangsbrief van 27 juni 2019 is een minimumlijstje opgenomen van wat overheden dan moeten kunnen of voorbereid moeten hebben. ${ }^{6}$ Gedacht kan worden aan het digitaal ontvangen van een vergunningaanvraag en het daarop beslissen conform de eisen op grond van de Omgevingswet. De feitelijke voorbereidingen worden de komende maanden dan ook steeds belangrijker.

In dit artikel worden enkele recente uitkomsten van de parlementaire behandeling geschetst. Voor een belangrijk deel van de wet- en regelgeving ligt dit najaar het primaat bij de senaat. Daarnaast zijn er andere relevante ontwikkelingen. Zo zal de Integrale Adviescommissie Omgevingswet een samenhangend advies uitbrengen over de diverse onderdelen van het wettelijk stelsel. Dat zal worden gevolgd door een reactie van het kabinet. Ook die informatie kan bij de parlementaire oordeelsvorming worden betrokken. Verder wordt in dit artikel ingegaan op (aanverwante) wet- en regelgeving die op de agenda van de Tweede Kamer staan. Tot slot wordt aandacht besteed aan de beschikbaarheid van integrale geconsolideerde versies van de Omgevingswet, de AMvB's en de Omgevingsregeling. Die versies geven een goed beeld van hoe de nieuwe regelgeving er op het moment van inwerkingtreding uit komt te zien.

\section{Tweede Kamerbehandeling van de Aanvullingswetten natuur en geluid}

\subsection{Aanvullingswet natuur ${ }^{7}$}

De mondelinge behandeling van dit wetsvoorstel in de Tweede Kamer was op 26 juni 2019. De behandeling was voorbereid door de vaste commissie voor Landbouw, Natuur en Voedselkwaliteit (LNV) en vond plaats met de Minister van LNV en de Minister van BZK als stelselverantwoordelijke minister. De behandeling was een week na het debat over de uitspraken van de Afdeling bestuursrechtspraak van de Raad van State over de programmatische aanpak stikstof (PAS) ${ }^{8}$ Die actuele ontwikkelingen werden uiteraard bij de behandeling van het wetsvoorstel betrokken. Ze hebben echter op wetsniveau niet tot veranderingen geleid. De wettelijke grondslag voor het vaststellen van 'een pro- gramma aanpak stikstof' is in het wetsvoorstel gehandhaafd. ${ }^{9}$

Het aanvullingswetsvoorstel voorziet in de inbouw van de Wet natuurbescherming in het stelsel van de Omgevingswet. Een kernwoord tijdens de behandeling was 'beleidsneutraal'. Hiermee is bedoeld dat de beleidskeuzes die ten grondslag lagen aan de Wet natuurbescherming, die in 2017 in werking is getreden, niet opnieuw ter discussie stonden. De bewindslieden gaven aan dat de normen en de instrumenten worden overgeheveld zonder afbreuk te doen aan het beschermingsniveau. Niet elke partij deelde dat uitgangspunt. Zo riep de Partij voor de Dieren op tot een fundamenteel andere omgang met de natuur en diende vijftien moties in met oproepen tot wijzigingen, onder meer rondom de jacht. Deze moties zijn echter niet aangenomen.

Inhoudelijk leidt de Aanvullingswet natuur dus niet tot grote veranderingen. Echter, ook de vertaling naar de instrumenten van de Omgevingswet is van betekenis. Het debat was dan ook geenszins inhoudsloos. Zo werd tijdens de behandeling door de Kamerleden De Groot (D66) en Dik-Faber (CU) een amendement ingediend dat ertoe strekt om een omgevingswaarde te introduceren voor de gunstige staat van instandhouding van 'de van nature in Nederland in het wild levende dier- en plantensoorten en de in Nederland voorkomende typen natuurlijke habitats en habitats van soorten'. ${ }^{10}$ De figuur van een omgevingswaarde brengt met zich dat een dergelijke waarde in 'objectieve termen' moet worden uitgedrukt. ${ }^{11}$ Dit betekent dat het criterium 'gunstige staat van instandhouding' zou moeten worden uitgewerkt voor individuele soorten en habitattypen. De Minister van LNV gaf aan dat die uitwerking zorgvuldig moet gebeuren en de nodige tijd vergt. Het amendement zou hierdoor pas later effect kunnen krijgen. Bij de stemming bleek er voor dit amendement geen meerderheid te zijn en werd het verworpen. Datzelfde lot trof enkele andere amendementen, ingediend door Kamerleden van diverse partijen, onder andere over het verbieden van windmolens en zonneparken in natuurgebieden, rondom de jacht, over een verbod op kappen tijdens de broed- of zoogperiode en over het toevoegen van een definitie van natuurlijke kenmerken van een Natura 2000-gebied. Wel aangenomen werd een amendement van het Tweede Kamerlid Bromet (GroenLinks) over het aan de Omgevingswet toevoegen van definities van dieren en planten. ${ }^{12}$

Het wetsvoorstel is op 4 juli 2019 met een ruime meerderheid aangenomen door de Tweede Kamer. ${ }^{13}$

Het voorgestelde vierde lid van art. 3.9 Ow. Zie art. 1.1 onderdeel J onder 2 Aanvullingswet natuur.

10. Kamerstukken II 2018/19, 34 985, nr. 23.

11. Art. 2.9 lid $3 \mathrm{Ow}$

12. Kamerstukken II 2018/19, 34 985, nr. 13

13. Met 117 stemmen voor: PvdA, DENK, 50PLUS, D66, VVD, SGP, CDA, ChristenUnie, PVV en FvD, en 33 stemmen tegen: GroenLinks, PvdD en SP 


\subsection{Aanvullingswet geluid ${ }^{14}$}

Op 27 juni 2019 is het voorstel voor de Aanvullingswet geluid plenair behandeld in de Tweede Kamer. De behandeling was voorbereid door de vaste commissie voor Infrastructuur en Waterstaat (IenW) en vond plaats met de Staatssecretaris van IenW en de Minister van BZK.

Dit wetsvoorstel regelt het opnemen van de regelgeving voor geluid afkomstig van infrastructuur (wegen en spoorwegen) en industrieterreinen in het stelsel van de Omgevingswet. Het voorstel regelt dat zowel voor de hoofdinfrastructuur van het Rijk als voor decentrale wegen en lokale spoorwegen. Geluidproductieplafonds (gpp's) worden in het voorstel als omgevingswaarde in het stelsel ingepast. Andere normstelling voor geluid, bijvoorbeeld afkomstig van bedrijfsactiviteiten of windmolens, maakt al onderdeel uit van het stelsel van de Omgevingswet. Dat geldt ook voor de regels over actieplannen van de diverse overheden voor geluid en de monitoring.

Geluid is voor diverse Kamerleden een ansprekend onderwerp. Dat zag je terug in het debat. Zo liet Van Gerven (SP) zelfgemaakte geluidsopnamen horen in de nabijheid van de A50 en maakte Von Martels (CDA) tijdens het debat gebruik van een decibelmeter en overwoog, toen hij waarden tot $85 \mathrm{~dB}$ mat, een motie om gpp's voor Kamerleden in te stellen. Van Eijs (D66) - het eerste slechthorende Kamerlid ${ }^{15}$ - zei over het belang van het tegengaan van geluidbelasting: 'Zelf ervaar ik elke dag hoe belastend geluid kan zijn. Ik ben altijd blij als de hoorapparaten weer uit mogen, dus ik kan me daar heel wat bij voorstellen.'

Inhoudelijk was er in het debat veel aandacht voor het te realiseren beschermingsniveau. Enkele Kamerleden vreesden voor aangescherpte normstelling met gevolgen voor bijvoorbeeld woningbouw of bedrijven. Andere drongen juist aan op aanscherping van de normstelling met het oog op de bescherming van de gezondheid. $\mathrm{Zij}$ verwezen naar onderzoek van de Wereldgezondheidsorganisatie en normstelling in andere landen (onder andere voor laagfrequent geluid). Beide bewindslieden wezen op het uitgangspunt van een gelijkwaardig beschermingsniveau en de mogelijkheid om per gebied in Nederland te voorzien in maatwerk. Verder zal de uitwerking van de normstelling nog aan de orde komen bij de voorhang van het Aanvullingsbesluit geluid dit najaar. Op die manier biedt dit wetsvoorstel het kader voor een uitgebalanceerde normstelling. In verband daarmee zijn twee moties aangehouden over het opnemen van volksgezondheid in dat besluit en het versoepelen van criteria voor geluidbeperkende maatregelen bij rijkswegen. ${ }^{16}$

Bij behandeling van dit wetsvoorstel zijn er geen amendementen ingediend. Het wetsvoorstel is op 2 juli 2019

14. Kamerstukken II 2018/19, 35 054, nrs. 1-2

15. Zie www.nrc.nl/nieuws/2017/05/18/.

16. Kamerstukken II 2018/19, 35 054, nrs. 10 en 12. met een ruime meerderheid aangenomen door de Tweede Kamer, met dezelfde stemverhouding als bij het voorstel voor de Aanvullingswet natuur. ${ }^{17}$

\section{Vervolg van het parlementaire proces}

\subsection{Eerste Kamer: nieuwe samenstelling, volle agenda}

Op 11 juni 2019 zijn de nieuwe leden van de Eerste Kamer geinstalleerd. Zoals in de inleiding is geschetst, wacht hun een volle agenda voor de behandeling van de wet- en regelgeving van de stelselherziening. Het voortouw ligt bij de vaste commissie voor Infrastructuur, Waterstaat en Omgeving (hierna: commissie IWO). De behandeling van het voorstel voor de Aanvullingswet natuur wordt samen met de vaste commissie voor Economische Zaken en Klimaat/Landbouw, Natuur en Voedselkwaliteit (EZK/LNV) voorbereid.

Diverse Kamerleden hebben uit hoofde van andere functies al kennis of ervaring opgedaan met het nieuwe stelsel. Dat kan de behandeling verder verrijken. Verder zal moeten worden afgewacht welke invloed de gewijzigde politieke samenstelling heeft op de (onderwerpen van de) behandeling. Duidelijk is in ieder geval dat de commissie IWO beoogt om tot een zorgvuldig proces van behandeling te komen. $\mathrm{Al}$ voor het zomerreces heeft dit geleid tot een technische briefing en een kennismakingsgesprek met minister Ollongren. Op de eerste vergadering na het zomerreces is het proces van de behandeling besproken en heeft de Kamer enkele randvoorwaarden geformuleerd. ${ }^{18}$ Komend najaar zijn de behandelingen voorzien van het voorstel voor de Invoeringswet, de voorstellen voor de Aanvullingswetten bodem en geluid, en de bijbehorende ontwerp-AMvB's. Voor het vervolg van de behandeling van het voorstel voor de Invoeringswet zullen een tweede deskundigenbijeenkomst en een technische briefing over het DSO worden gepland. Verder zal de Kamer een start maken met de schriftelijke behandeling van de voorstellen voor de Aanvullingswetten natuur en grondeigendom. Afronding van de behandeling van die voorstellen is begin volgend jaar voorzien.

Verder zal de Integrale Adviescommissie Omgevingswet dit najaar een advies uitbrengen, waarin de wetgevingsproducten van het stelsel die aan het parlement zijn voorgelegd in samenhang worden beschouwd. ${ }^{19}$ Dit zal worden gevolgd door een kabinetsreactie. De Eerste en Tweede Kamer kunnen die informatie betrekken bij hun oordeelsvorming over de transitie naar het nieuwe stelsel. Zoals in de inleiding is geschetst, is daarbij

17. Met 117 stemmen voor: PvdA, DENK, 50PLUS, D66, VVD, SGP, CDA, ChristenUnie, PVV en FvD, en 33 stemmen tegen: GroenLinks, PvdD en SP.

18. Brief van 13 september 2019, kenmerk $164662.11 u$, p. 1 en 2 , www.eerstekamer.nl/kamerstukdossier/omgevingsrecht.

19. Kamerstukken I 2018/19, 33 118, AO, p. 7. 
sprake van een stapsgewijs proces. Dit houdt in dat het kabinet op diverse momenten aan het parlement zal rapporteren over de stand van zaken. Tot slot is voorzien in een helder afwegingsmoment voor het parlement.

\subsection{Vervolg behandeling Invoeringswet}

Dit najaar zal voor de Eerste Kamer het accent liggen op de behandeling van de diverse wetsvoorstellen en ontwerpbesluiten. Een belangrijk onderdeel daarvan is het vervolg van de behandeling van het voorstel voor de Invoeringswet. Zoals in de vorige aflevering ${ }^{20}$ van deze rubriek is besproken, is het voorstel voor de Invoeringswet op 7 maart aangenomen door de Tweede Kamer. Vervolgens heeft de Eerste Kamer, in de samenstelling van de vorige zittingsperiode, het voorlopig verslag uitgebracht..$^{21}$ Dit voorlopig verslag is tot stand gekomen na een zorgvuldig voorbereidingsproces met technische briefings, externe ondersteuning en een deskundigenbijeenkomst, waarvoor diverse vertegenwoordigers van andere overheden en uitvoeringsorganisaties waren uitgenodigd.

In het voorlopig verslag kwamen verschillende onderwerpen aan bod. Een deel daarvan had betrekking op specifiek in het voorstel voor de Invoeringswet geregelde onderwerpen. Het merendeel ging over algemene onderwerpen binnen het stelsel, zoals participatie en de balans tussen het beschermen en benutten van de leefomgeving. Daarnaast lag de focus op de ontwikkeling van het DSO en de voorbereiding op de inwerkingtreding van het stelsel. De regering heeft de vragen beantwoord in de memorie van antwoord. ${ }^{22}$

\section{- Participatie}

Bij de Tweede Kamerbehandeling was participatie een belangrijk onderwerp, in het bijzonder bij de vergunningverlening voor buitenplanse omgevingsplanactiviteiten. Dat heeft geleid tot een amendement waarin de gemeenteraad de bevoegdheid krijgt om gevallen aan te wijzen waarin participatie verplicht is. ${ }^{23}$ Ook in het voorlopig verslag krijgt dit onderwerp de nodige aandacht. De leden van de fracties van de VVD, D66, de SP, GroenLinks en de ChristenUnie stellen hier vanuit verschillende invalshoeken vragen over. $\mathrm{Zij}$ vragen onder andere waarom er niet meer eisen worden gesteld aan participatie. In de memorie van antwoord wordt benadrukt dat de Omgevingswet geen eisen stelt aan de vorm van participatie, zodat de initiatiefnemer (en het bevoegd gezag) een aanpak kan kiezen die past bij de betrokken activiteit en de lokale situatie. Ook worden vragen gesteld over de verhouding tussen participatie en de rol van de gemeenteraad of provinciale staten. De regering antwoordt dat participatie kan bijdragen aan een zorgvuldige voorbereiding, maar nooit in de plaats kan komen van de belangenafweging die het bevoegd

20. H.W. de Vos, De stand van de stelselherziening: de parlementaire behandeling als opmaat naar een zorgvuldige invoering, TO 2019, afl. 1, p. 5 e.v.

21. Kamerstukken I 2018/19, 34 986, F.

22. Kamerstukken I 2018/19, 34 986, G.

23. Kamerstukken II 2018/19, 34 986, nr. 56. gezag (de lokale democratie) moet maken. Verder zijn er vragen over de wijze waarop initiatiefnemers geinformeerd worden over verplichte participatie bij vergunningen voor buitenplanse omgevingsplanactiviteiten. In het antwoord wijst de regering erop dat de gemeente in het vooroverleg de initiatiefnemer kan informeren over de participatieplicht. Daarnaast moet de gemeente een generieke lijst publiceren van vergunningen waarvoor de participatieplicht gaat gelden. Naar aanleiding van vragen over het participatieprotocol antwoordt de regering dat de Inspiratiegids Participatie verder zal worden uitgebreid met goede voorbeelden.

- Balans beschermen en benutten, bestuurlijke verhoudingen

Een algemeen thema van de stelselherziening is de balans tussen beschermen en benutten. Ook in het voorlopig verslag kwam dit aan de orde. Een aantal fracties vroeg of er voldoende waarborgen zijn dat de balans niet doorslaat naar benutten. In de memorie van antwoord is toegelicht hoe de balans binnen het wettelijk systeem kan worden bereikt, en dat deze balans via monitoring en evaluatie in de gaten gehouden zal worden. Dit is in lijn met de beantwoording van vergelijkbare vragen bij de Tweede Kamerbehandeling. Er zijn ook diverse vragen gesteld over de bestuurlijke verhoudingen, onder meer bij belangrijke opgaven als energietransitie of het tegengaan van klimaatverandering. In de memorie van antwoord wordt aangegeven dat de regering geen spanning ziet met het uitgangspunt van 'decentraal, tenzij' Ook bij die thema's zullen decentrale overheden een belangrijke rol vervullen. Aanpassingen van steden aan het veranderende klimaat, het aardgasvrij maken van wijken of het plaatsen van laadpalen in de openbare ruimte zijn zonder meer taken voor het lokale bestuur. Waar dat efficiënt is, kan ook tussen gemeenten of provincies worden samengewerkt. In enkele antwoorden wordt ingegaan op de ruimte die de Omgevingswet biedt voor samenwerking en coactorschap. Voor zover er sprake is van overstijgende belangen en dat nodig is voor een doelmatige of doeltreffende taakuitoefening kan op provinciaal of nationaal niveau worden voorzien in instructieregels of algemene regels. Voor de totstandkoming van die regels biedt de Omgevingswet het kader en de procedurele waarborgen.

\section{- Digitaal Stelsel Omgevingsmet}

Een belangrijk thema was ook het DSO. De leden van de fracties van de VVD, het CDA, D66, de SP, de PvdA, GroenLinks en de ChristenUnie hebben hier een serie vragen over gesteld. $\mathrm{Zij}$ vroegen onder meer of het DSO voldoende adaptief is, en hoe het DSO structureel up-to-date wordt gehouden. In de antwoorden wordt gemeld dat het DSO adaptief is en nieuwe ontwikkelingen kan accommoderen. Voor de inhoud van de informatie wordt gebruik gemaakt van de generieke digitale infrastructuur voor het bekendmaken en beschikbaar stellen van publicaties. Overheden zijn zelf verantwoordelijk voor de inhoud van publicaties en het up-to-date houden daarvan. Het DSO zorgt voor een 
gebruiksvriendelijke ontsluiting van die informatie. Enkele fracties stelden vragen over de leesbaarheid en toegankelijkheid van het DSO voor laaggeletterden of fysiek beperkten. De regering vermeldt in het antwoord dat daarvoor de wettelijke eisen op het gebied van digitale toegankelijkheid worden gevolgd.

Uiteraard waren er ook veel vragen over de stand van zaken van de ontwikkeling van het DSO. Diverse fracties vroegen of de verschillende onderdelen van het DSO op tijd worden opgeleverd en of er voldoende geoefend kan worden met het DSO. In de antwoorden wordt aangegeven dat de landelijke voorziening eind 2019 wordt opgeleverd en dat de planning haalbaar is om de landelijke voorziening van het DSO in 2020 beschikbaar te hebben. Dat geeft andere overheden naar verwachting voldoende tijd om op deze landelijke voorziening aan te sluiten en te oefenen. Het parlement zal daarvan regelmatig op de hoogte worden gehouden. In de antwoorden op de vragen over het advies van het Bureau ICT-toetsing (BIT) bevestigt de regering de toezegging naar aanleiding van de motie Ronnes ${ }^{24}$ om het BIT aan het einde van het jaar een update te laten doen.

\section{- Implementatie}

De leden van de VVD-, CDA-, D66- en PvdA-fractie hebben vragen gesteld over de monitoring en de voortgang van de transitie naar het nieuwe stelsel. Voor het antwoord op deze vragen wordt in de memorie van antwoord verwezen naar de voortgangsbrief van 27 juni 2019 over de monitoring van de implementatie. ${ }^{25}$ Daarin wordt uitgebreid ingegaan op de stand van zaken van de voorbereiding op de invoering. Ook is daarbij een minimumlijst opgenomen van activiteiten die overheden bij inwerkingtreding moeten kunnen verrichten. Enkele fracties vroegen welke criteria bij de evaluatie van de Omgevingswet worden betrokken, of de evaluatie door een onafhankelijke instantie wordt uitgevoerd, en of ze de opzet van de evaluatie mogen ontvangen. In het antwoord wordt het belang van een onafhankelijke evaluatie onderschreven. Ook wordt aangegeven dat de balans tussen het beschermen en benutten van de leefomgeving een belangrijk criterium vormt voor de evaluatie, naast de verbeterdoelen van de stelselherziening. De regering zegt toe de aanpak van de evaluatie met de Kamer te delen.

\subsection{Tweede Kamer: nog belangrijke onderwerpen op de agenda}

Hoewel de Tweede Kamer al veel producten van het nieuwe stelsel heeft behandeld, staan er dit najaar nog belangrijke onderwerpen op de agenda. Dat geldt in de eerste plaats voor het voorstel voor de Aanvullingswet grondeigendom. Daarnaast geldt dat voor de voorhang van de ontwerpbesluiten. In het kader van de voorhangprocedure van het ontwerp van het Invoeringsbesluit heeft de Tweede Kamer al voor het zomerreces inbreng

24. Kamerstukken II 2018/19, 34 986, nr. 26

25. Kamerstukken I 2018/19, 33 118, AV. geleverd. De behandeling van de voorgehangen Aanvullingsbesluiten bodem en natuur is in september gestart, de overige ontwerpen van de aanvullingsbesluiten volgen zodra die aanhangig zijn.

Buiten het bouwproces van de stelselherziening omgevingsrecht zijn er bij de Tweede Kamer twee wetsvoorstellen aanhangig die wijzigingen van de Omgevingswet bevatten. Het gaat om de Wet elektronische publica$\operatorname{ties}^{26}$ en de wijziging van de Algemene wet bestuursrecht en enkele andere wetten in verband met het nieuwe omgevingsrecht en nadeelcompensatierecht. ${ }^{27}$ Het eerste voorstel bevat onder meer regels over de elektronische bekendmaking van besluiten en regelingen. Het tweede voorziet onder andere in een algemene coördinatieregeling. Beide wetsvoorstellen hebben een brede betekenis, die verder strekt dan het omgevingsrecht. De voorgestelde wijzigingen van de Omgevingswet zullen echter tegelijk met het stelsel van de Omgevingswet in werking treden.

De komende jaren zullen steeds meer nieuwe beleidsontwikkelingen en de implementatie van Europese of internationale regelgeving uitvoering krijgen via wijzigingen van onderdelen van het stelsel van de Omgevingswet. Voor beleidsontwikkelingen van het Rijk die gevolgen hebben voor de fysieke leefomgeving zal de nationale omgevingsvisie (NOVI) een belangrijk kader bieden. Het ontwerp daarvan is in juni gepresenteerd en aan de Tweede Kamer gezonden. ${ }^{28}$ Een andere recente ontwikkeling is het vaststellen van het Klimaatakkoord, dat in juli aan het parlement is gezonden. ${ }^{29}$ De uitvoering daarvan zal voor een deel, bijvoorbeeld enkele maatregelen in het kader van de energietransitie voor de gebouwde omgeving, via de instrumenten en regels van het nieuwe stelsel verlopen. De komende tijd zal het kabinet in kaart brengen welke wijzigingen of aanvullingen van de wet- en regelgeving er nodig zijn. ${ }^{30}$

\section{Doorkijk naar de nieuwe regels}

De afgelopen periode is het stelsel van de Omgevingswet verder uitgekristalliseerd. Om een beeld te krijgen van hoe de Omgevingswet er bij inwerkingtreding uit zal zien, is er een update van de integrale geconsolideerde versie beschikbaar. ${ }^{31}$ Dit is een bijgewerkte versie van de

26. Het bij koninklijke boodschap van 6 juni 2019 aangeboden voorstel van wet tot wijziging van de Bekendmakingswet en andere wetten in verband met de elektronische publicatie van algemene bekendmakingen, mededelingen en kennisgevingen (Wet elektronische publicaties) (Kamerstukken 35 218).

27. Het bij koninklijke boodschap van 10 juli 2019 aangeboden voorstel van wet tot wijziging van de Algemene wet bestuursrecht en enkele andere wetten in verband met het nieuwe omgevingsrecht en nadeelcompensatierecht (Kamerstukken 35 256).

28. Kamerstukken II 2018/19, 34 682, nr. 27.

29. Kamerstukken II 2018/19, 32 813, nr. 342.

30. Kamerstukken II 2018/19, 32813 , nr. 348, p. 2 en 3.

31. Zie www.omgevingswetportaal.nl/wet-en-regelgeving/wet. 
Omgevingswet, inclusief de wijzigingen van de voorstellen voor de Invoeringswet en de aanvullingswetten. Met het aannemen door de Tweede Kamer van de voorstellen voor de Aanvullingswetten geluid en natuur is de tekst weer completer geworden. ${ }^{32}$

Dit najaar zullen er ook geïntegreerde versies verschijnen van de vier AMvB's op grond van de Omgevingswet. Daarin zullen de voorhangversies van het Invoeringsbesluit en de Aanvullingsbesluiten bodem, natuur, geluid en grondeigendom zijn verwerkt. Verder wordt dit najaar de vaststelling en publicatie van de Omgevingsregeling verwacht. Met de publicatie van de Omgevingswet en de vier AMvB's is het hoofdspoor van de bouw van het nieuwe stelsel afgerond. Tot slot zal, volgens de planning, dit jaar het ontwerp van de Invoeringsregeling voor openbare consultatie op internet worden gepubliceerd. Dan zal ook van de Omgevingsregeling een geconsolideerde versie beschikbaar zijn.

De beschikbaarheid van al deze teksten zorgt ervoor dat nu al in belangrijke mate inzichtelijk is hoe het nieuwe stelsel eruit komt te zien. De teksten zullen komend jaar worden geüpdatet, wanneer er nieuwe ontwikkelingen zijn of regels definitief zijn vastgesteld. Deze integrale geconsolideerde versies zijn waardevol voor iedereen die zich voorbereidt op de inwerkingtreding van het stelsel.

32. In de integrale geconsolideerde versie zijn ook de wijzigingen van de voorstellen voor de Aanvullingswet grondeigendom, de Wet elektronische publicaties (Kamerstukken 35 218) en de wijziging van de Algemene wet bestuursrecht (Kamerstukken 35 256) verwerkt. Deze wetsvoorstellen zijn nog in behandeling bij de Tweede Kamer en kunnen dus nog wijzigingen ondergaan. 